14

\title{
Улучшение растворения лидокаина посредством диспергирования методом быстрого расширения сверхкритического раствора
}

\author{
() И.В. Кузнецова, Н.С. Сандугей, И.И. Гильмутдинов, И.М. Гильмутдинов, А.Н. Сабирзянов \\ Казанский национальный исследовательский технологический университет, \\ 420015 Казань, Татарстан, Россия \\ e-mail: irina301086@gmail.com
}

Поступило в Редакцию 16 марта 2021 г.

В окончательной редакции 18 мая 2021 r.

Принято к публикации 30 мая 2021 г.

Было проведено экспериментальное исследование измельчения лидокаина методом быстрого расширения сверхкритических растворов (метод RESS). Эксперименты проведены в диапазоне давлений 10-35 MPa и температур 308-333 К. Проведен анализ морфологии и размеров частиц, а также влияния на них режимных параметров процесса. Проведен качественный и количественный спектрофотометрический анализ. В среде фосфатного буферного раствора, имитирующего плазму, был проведен тест „Растворение“, показавший, что уменьшение размера частиц дало повышенный выход препарата за более короткий промежуток времени по сравнению с оригинальным лекарственным средством, не подвергавшимся обработке.

Ключевые слова: сверхкритический флюид, микрочастицы, спектрофотометрический анализ, лидокаин.

DOI: 10.21883/JTF.2021.11.51544.61-21

\section{Введение}

Рост числа терапевтически активных, но относительно нерастворимых соединений, получаемых при разработке новых препаратов, создает серьезные препятствия в обеспечении необходимого уровня лечебного эффекта данных веществ. Бесспорно, для его достижения малорастворимые в водной среде препараты должны применяться в больших дозах, что, в свою очередь, ведет к возникновению большого числа нежелательных побочных эффектов и в случае сильнодействующих препаратов представляет серьезную проблему.

Скорость и степень, с которыми активный лекарственный ингредиент или терапевтический компонент препарата поглощается из фармацевтического продукта и становится доступным в месте действия, можно повысить различными способами: производством его солевых форм, формированием полиморфов и т. п. Однако наиболее эффективным и простым способом является микронизация фармацевтической субстанции. Микронизация гидрофобных лекарственных препаратов позволит существенно повысить скорость их растворения в водных средах, которая напрямую зависит от размеров частиц фармацевтической субстанции, а, следовательно, и их биодоступность, снизить массу, тем самым сокращая негативное действие из-за побочных эффектов.

Преимуществами методов микронизации с использованием сверхкритических флюидных сред является возможность получения однородных частиц с определенными физико-химическими свойствами, размерами и морфологией, регулируемыми посредством изменений значений режимных параметров осуществляемого одностадийного процесса, экологическая безопасность.

Основной целью настоящей работы является исследование влияния диспергирования фармацевтической субстанции лидокаина методом быстрого расширения сверхкритических растворов (метод RESS) на уровень еe растворения. Для достижения данной цели впервые были решены следующие задачи: проведены четыре серии экспериментов по изучению влияния режимных параметров по диспергированию фармацевтической субстанции лидокаина методом RESS, осуществлен анализ размеров полученных частиц. Проведен качественный и количественный анализ продиспергированного лидокаина на УФ-спектрофотометре ПЭ-5400УФ. Фармацевтическая субстанция в ходе обработки методом RESS не подверглась термическому разложению, молекулярной деструкции или каким-либо другим негативным воздействиям. В среде фосфатного буферного раствора, имитирующего плазму, был впервые проведен тест „Растворение“ для фармацевтической субстанции лидокаин.

\section{1. Экспериментальная часть}

\section{1. Методика исследования и установка}

Для диспергирования лидокаина в настоящей работе используется установка RESS-100 (рис. 1) фирмы Thar Technologies Inc. (США, официальный дистрибьютор на территории Российской Федерации ЗАО „ШАГ“) Методика проведения эксперимента описана в предыдущих работах и диссертации $[1,2]$. 


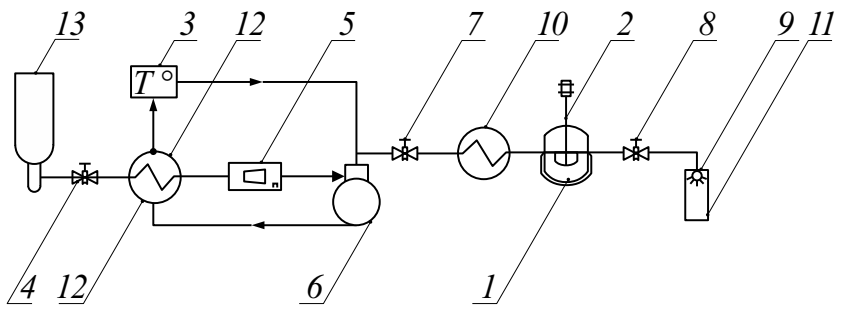

Рис. 1. Схема экспериментальной установки Thar RESS100: 1 - насытитель, 2 - мешалка, 3 - термостат, 4, 7, 8 - вентили, 5 - расходомер, 6 - насос высокого давления, $9-$ расширительное устройство, $10-$ электрический нагреватель, 11 - камера расширения, 12 - охлаждающий теплообменник, 13 - баллон с диоксидом углерода; для охлаждения цилиндров насоса высокого давления 6 и углекислого газа в теплообменнике 12 включается термостат 3.

Канал расширения изготовлен из сапфирового стекла: диаметр отверстия $150 \mu \mathrm{m}$, длина канала $1000 \mu \mathrm{m}$.

\section{2. Методика анализа размеров и дисперсности частиц}

Порошки, получаемые в результате диспергирования субстанций, состоят из частиц, обладающих неправильными геометрическими формами и различными размерами.

Пробу исследуемого порошка помещают на предметное стекло в виде монослоя. Для исключения агрегирования частиц и их слипания допускается легкое механическое растирание или жидкое диспергирование с использованием поверхностно-активных веществ (ПАВ), подбираемых индивидуально.

В настоящей работе изучение частиц проведено микроскопическим методом на оптическом микроскопе Levenhuk D320L. Относительная погрешность измерений для 100 измерений и доверительной вероятности $P=0.95$ равна $1.5 \%$.

\section{3. Методика анализа лидокаина на УФ-спектрофотометре}

В Государственной фармакопее (ГФ) Российской Федерации физические методы (определение температуры плавления) анализа и титрование являются официальными для анализа лидокаина - статей о применении каких-либо других методов в ГФ РФ нет. Таким образом, на основе анализа имеющейся литературы была разработана УФ-спектрофотометрическая методика установления подлинности, чистоты и количественного определения лидокаина. УФ-метод является наиболее удобным и легким для стандартной процедуры анализа $[3,4]$.

В ходе проведения анализов в качестве чистых растворителей используется 95\% этанол и фосфатный буферный раствор с рН 7. Для получения спектра исследуемого образца выполняются последовательно 2 процедуры:
1) сканирование нулевой линии: готовится холостая проба, представляющая собой чистый растворитель, в котором в дальнейшем будет анализироваться исследуемое вещество, т.е. нулевой образец, не содержащий аналита. Образец холостой пробы наливают в кварцевую кювету и устанавливают на пути светового пучка в кюветное отделение, которое затем плотно закрывают;

2) сканирование исследуемого образца: после выполнения сканирования нулевой линии исследуемый образец помещают в рабочую зону и запускают процесс его сканирования, в ходе которого в окне программы отображается график спектра и таблица данных со значениями длин волн, оптической плотности и пропускания. Для приготовления исследуемого образца взвешивают $100 \mathrm{mg}$ с погрешностью $0.005 \mathrm{mg}$ исследуемого вещества, растворяют в чистом растворителе, объем доводят до $100 \mathrm{ml}$, а затем разводят тем же самым растворителем до концентрации $0.15 \mathrm{mg} / \mathrm{ml}$.

На спектральной кривой определяется аналитическая длина волны, соответствующая длине волны максимального поглощения.

\section{4. Качественный анализ. Методика испытания на подлинность}

С помощью УФ-спектрофотометра и ПО „Scan54“ получают и проводят сравнение спектров поглощения растворов исходного и микронизированного лекарственного средства (ЛС) в одном и том же растворителе. Обработанное ЛС признается идентичным исходному в случае наблюдения в рабочей области спектра совпадения точек максимумов, минимумов, плеч и точек перегиба.

\section{5. Методика проведения теста „Растворение“}

Тест „Растворение“ проводится на цифровой магнитной мешалке с подогревом модели WiseStir MSH-20D фирмы DAIHAN Scientific Co. (Республика Корея).

В лабораторный сосуд помещают определенный объем среды растворения $(500 \mathrm{ml})$ и ставят на нагревательную поверхность магнитной мешалки. В качестве среды растворения применяется фосфатный буферный раствор с рН 7, имитирующий плазму. Температура среды растворения контролируется на протяжении всего исследования и составляет $(37.0 \pm 0.5)^{\circ} \mathrm{C}$.

Точную навеску лекарственного средства $(0.25 \mathrm{~g})$ добавляем в среду растворения. Отбор проб осуществляется из зоны сосуда для растворения, находящейся на половине расстояния между поверхностью среды растворения и лопасти мешалки и на расстоянии не менее $1 \mathrm{~cm}$ от стенок сосуда для растворения. Отбор проб осуществляется в начальный момент времени, когда анализируемое лекарственное средство было помещено в среду растворения, и через каждые последующие 10 min до достижения полного растворения. 
Отобранные пробы наливают в кварцевые кюветы и последовательно устанавливают на пути светового пучка в кюветное отделение УФ-спектрофотометра, которое затем плотно закрывают. Анализ проводится на ранее найденной аналитической длине волны и с помощью сохраненных файлов с построенными калибровочными графиками. Проводится измерение оптической плотности анализируемых образцов. Далее рассчитывается значение концентрации.

ЛС считается полностью растворившимся, когда его концентрация в среде растворения достигнет значения $0.5 \mathrm{mg} / \mathrm{ml}$.

\section{6. Материалы}

В настоящей работе в качестве исследуемого вещества используется лидокаин $\mathrm{C}_{14} \mathrm{H}_{22} \mathrm{~N}_{2} \mathrm{O}$ (белый кристаллический порошок), полученный для исследования от компании SIGMA-ALDRICH, с чистотой более 98\%. Молекулярный вес $234.3373 \mathrm{~g} / \mathrm{mol}$, температура плавления $68.5^{\circ} \mathrm{C}$.

Согласно ГФ РФ, лидокаин классифицируется как „умеренно растворимый“ в воде, т.е. для растворения 1 части лидокаина потребуется 30-100 частей растворителя.

В качестве сверхкритического растворителя использован диоксид углерода с чистотой 99\% (ГОСТ 8050-85). Критические параметры $\mathrm{CO}_{2}: T_{\mathrm{cr}}=303.9 \mathrm{~K}$, $P_{\text {cr }}=7.38 \mathrm{MPa}$.

В качестве раствора сравнения при спектрофотометрическом анализе использовался этиловый спирт 95\% (этанол) (ГОСТ 18300-72): смесь этанола с водой, содержащая по объему 95\% этилового спирта. Является растворителем для ряда ЛС, в том числе и лидокаина. Как было сказано выше, лидокаин растворим в спирте, хлороформе, бензоле и эфире. Однако все указанные растворители, кроме этанола, являются высокотоксичными веществами, не используемыми в фармацевтике. Этим и обусловлен выбор этилового спирта в качестве раствора сравнения.

В качестве раствора сравнения при спектрофотометрическом анализе и среды растворения, имитирующей плазму при проведении теста „Растворение“, используется фосфатный буферный раствор с $\mathrm{pH} 7.0$ при температуре $20^{\circ} \mathrm{C}$ : прозрачная бесцветная подвижная жидкость без запаха (ТУ 2642-071-23050963-2009). Данный растворитель использовался при анализе микронизированного лидокаина.

Данная буферная система образована одно- и двузамещенными солями фосфорной кислоты, где однозамещенные соли представлены слабыми кислотами, а двузамещенные располагают заметными щелочными свойствами.

\section{2. Результаты и их обсуждение}

На экспериментальной установке RESS-100 проведено диспергирование лидокаина с использованием диоксида углерода в качестве сверхкритического растворителя. Всего было проведено четыре серии экспериментов со следующими параметрами процесса:

1. Серия экспериментов № 1. Давление в системе составляет $20 \mathrm{MPa}$, диапазон температур насытителя от 308 до $333 \mathrm{~K}$.

2. Серия экспериментов № 2. Температура насытителя составляет $313 \mathrm{~K}$, диапазон давлений в системе от 10 до $35 \mathrm{MPa}$.

3. Серия экспериментов № 3. Давление в системе составляет $35 \mathrm{MPa}$, диапазон температур насытителя от 308 до $333 \mathrm{~K}$.

4. Серия экспериментов № 4. Температура насытителя составляет $333 \mathrm{~K}$, диапазон давлений в системе от 10 до $35 \mathrm{MPa}$.

Результаты измерений представлены в табл. 1.

Частицы порошка, полученного в сериях экспериментов № 1 и № 4, оказались настолько мелкими, что

Таблица 1. Условия проведения и результаты диспергирования лидокаина методом Rapid Expansion of Supercritical Solutions (RESS)линией указан необработанный лидокаин, штриховой - лидокаин, обработанн

\begin{tabular}{c|c|c|c|c|c}
\hline № & $T_{\text {sat }}, \mathrm{K}$ & $T_{\text {ed }}, \mathrm{K}$ & $P_{\text {sat }}, \mathrm{Pa}$ & $d_{i}, \mu \mathrm{m}$ & $d_{p}, \mu \mathrm{m}$ \\
\hline \multicolumn{5}{c}{ Серия экспериментов № 1} \\
\hline 1 & 308 & 338 & 20 & $1.4-5.4$ & 2.3 \\
2 & 313 & & & $1.3-3.8$ & 2.2 \\
3 & 318 & & & $1.1-3.9$ & 2.1 \\
4 & 323 & & & $1.2-3.5$ & 1.9 \\
5 & 328 & & & $1.2-3.1$ & 1.9 \\
6 & 333 & & & $1.1-2.5$ & 1.7 \\
\hline
\end{tabular}

Серия экспериментов № 2

\begin{tabular}{l|l|l|l|l|l}
\hline 1 & 313 & 338 & 10 & $1.1-2.5$ & 1.6 \\
2 & & & 15 & $1.2-2.8$ & 1.8 \\
3 & & & 20 & $1.3-3.8$ & 2.2 \\
4 & & & 25 & $1.5-4.6$ & 2.2 \\
5 & & & 30 & $1.2-6.6$ & 2.4 \\
6 & & & 35 & $1.4-6.4$ & 2.6 \\
\hline
\end{tabular}

Серия экспериментов № 3

\begin{tabular}{l|l|l|l|l|l}
\hline 1 & 308 & 338 & 35 & $1.6-6.5$ & 2.8 \\
2 & 313 & & & $1.4-6.4$ & 2.6 \\
3 & 318 & & & $1.4-4.7$ & 2.1 \\
4 & 323 & & & $1.2-3.2$ & 1.9 \\
5 & 328 & & & $1.1-2.9$ & 1.7 \\
6 & 333 & & & $1.1-2.5$ & 1.6 \\
\hline
\end{tabular}

Серия экспериментов № 4

\begin{tabular}{l|l|l|l|l|l}
\hline 1 & 333 & 338 & 10 & - & - \\
2 & & & 15 & $1.0-2.9$ & 1.6 \\
3 & & & 20 & $1.1-2.5$ & 1.7 \\
4 & & & 25 & $1.2-3.7$ & 2.9 \\
5 & & & 30 & $1.1-3.8$ & 1.8 \\
6 & & & 35 & $1.1-2.5$ & 1.6
\end{tabular}

Примечание. $T_{e d}-$ температура подогрева расширительного устройства 9, (рис. 1). 

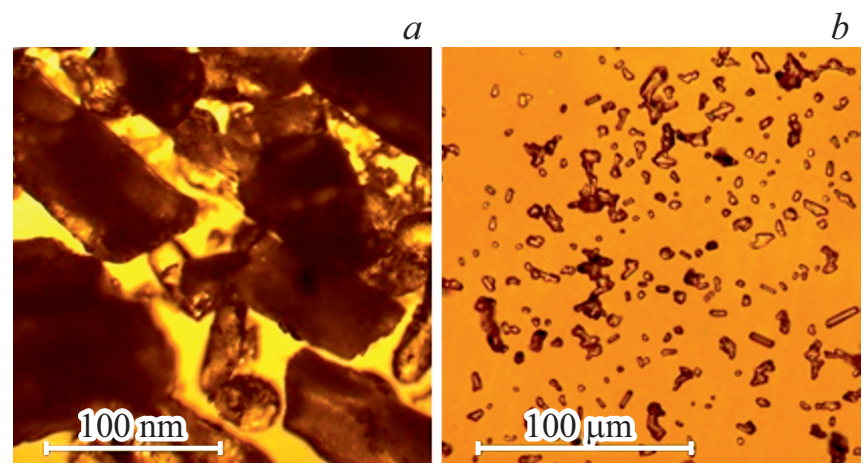

Рис. 2. Частицы лидокаина: $a-$ необработанные, средний размер $108.12 \mu \mathrm{m}$ (40-кратное увеличение); $b-$ после измельчения методом RESS средний размер частиц $1.65 \mu \mathrm{m}$ (400-кратное увеличение).

оптической мощности микроскопа, используемого для анализа размеров и морфологии исследуемых частиц, не хватило для определения их среднего размера.

На рис. 2 представлены частицы лидокаина до и после измельчения методом RESS.

Анализ проведен на оптическом микроскопе Levenhuk D320L c 400-кратным увеличением. Показано уменьшение средних размеров более чем в 60 раз.

\section{1. Влияние температуры на размер частиц}

Как видно из рис. 3, с ростом температуры при более высоком давлении размер полученных частиц меняется значительнее. Так, если на изобаре $20 \mathrm{MPa}$ средний размер частиц от 308 до $333 \mathrm{~K}$ уменьшается с 2.3 до $1.7 \mu \mathrm{m}$, то при $35 \mathrm{MPa}$ средний размер частиц уменьшается уже с 2.8 до $1.6 \mu \mathrm{m}$.

Это можно объяснить тем, что более высокое значение давления в системе приводит к увеличению массового расхода раствора и вызывает уменьшение времени пребывания в канале расширения. Таким образом, будет уменьшено время для роста частиц в канале расширения. Кроме того, с увеличением температуры экстракции, согласно работе [3], увеличивается растворимость лидокаина в сверхкритическом диоксиде углерода, что, в свою очередь, ведет к увеличению степени пересыщения. В насыщенном растворе образуется большее количество критических зародышей, а это впоследствии позволяет получать большее количество меньших по размеру частиц, что наглядно отражено на гистограммах распределения среднего размера частиц в данных сериях экспериментов: с ростом температуры значительно увеличивается количество частиц с размерами $1-2 \mu \mathrm{m}$, а при $333 \mathrm{~K}$ наблюдается незначительный процент частиц с размерами до $3 \mu \mathrm{m}$ и полное отсутствие частиц большего размера. Повышается дисперсность получаемого порошка, частицы приобретают правильную сферическую форму, наблюдается значительное уменьшение их агломераций.

\section{2. Влияние давления на размер частиц}

Как видно из рис. 4, размер полученных частиц на изотерме $313 \mathrm{~K}$ с ростом давления увеличивается. Раствор является насыщенным при небольших параметpax процесса, что наглядно отражено на гистограмме распределения среднего размера частиц: в порошках, полученных при давлениях 10 и $15 \mathrm{MPa}$, наблюдается значительный процент частиц с размерами $1-2 \mu \mathrm{m}$. Однако дальнейший рост давления приводит к возрастанию размера частиц: значительно сокращается процент частиц с размерами $1-2 \mu \mathrm{m}$, наряду с этим увеличивается количество частиц с размерами 2.5-3.0 $\mu \mathrm{m}$, а при $20 \mathrm{MPa}$ наблюдается появление частиц с размерами от $3 \mu \mathrm{m}$ и более.

На рис. 5 отчетливо видно неоднозначное влияние изменения давления в системе на размер получаемых частиц фармацевтической субстанции на изотерме $333 \mathrm{~K}$.
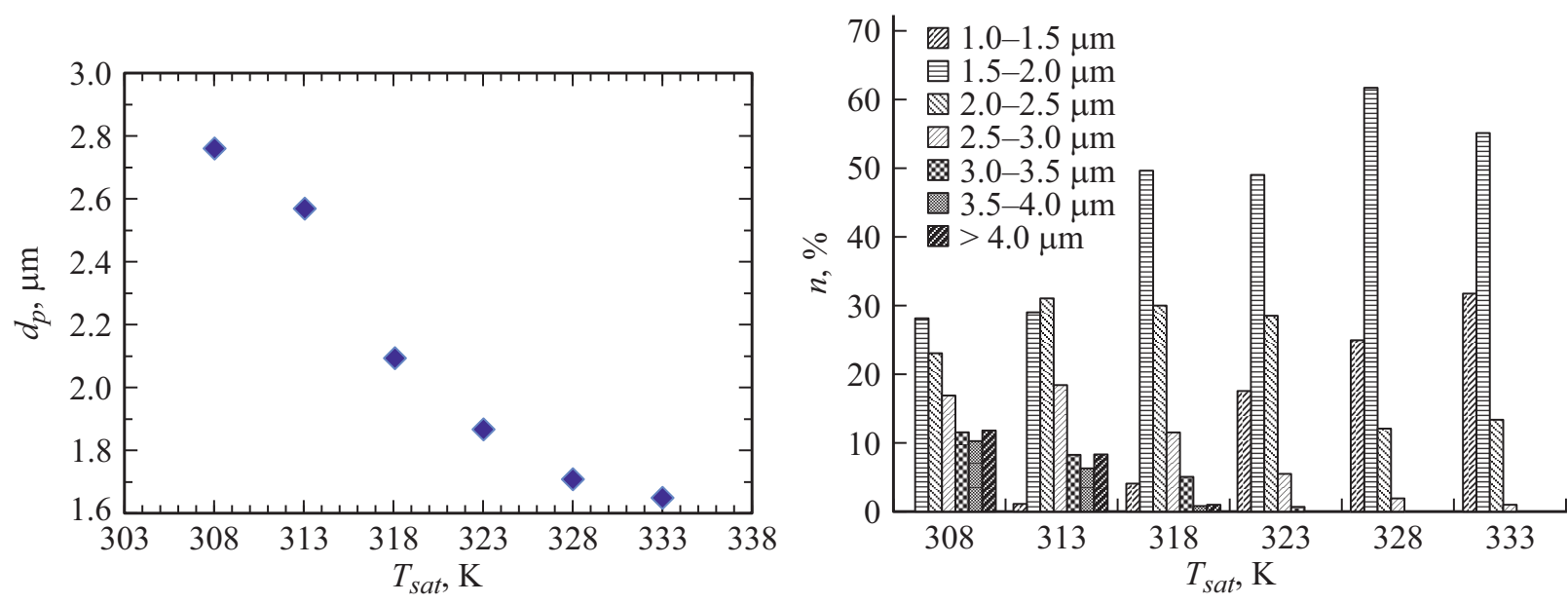

Рис. 3. Зависимость среднего размера частиц от температуры насытителя и гистограмма распределения среднего размера частиц в серии экспериментов № 3 при давлении в системе $35 \mathrm{MPa}$. 

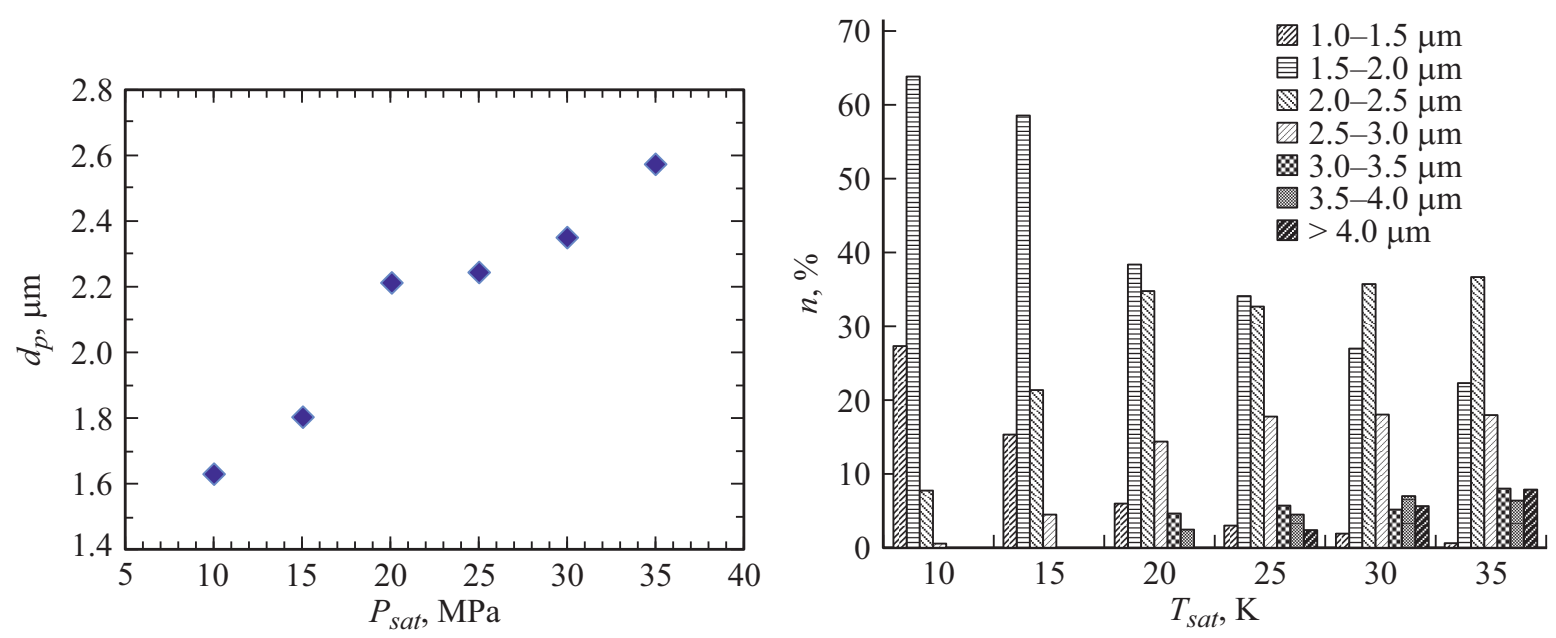

Рис. 4. Зависимость среднего размера частиц от давления в системе и гистограмма распределения среднего размера частиц в серии экспериментов № 2 при температуре насытителя $313 \mathrm{~K}$.
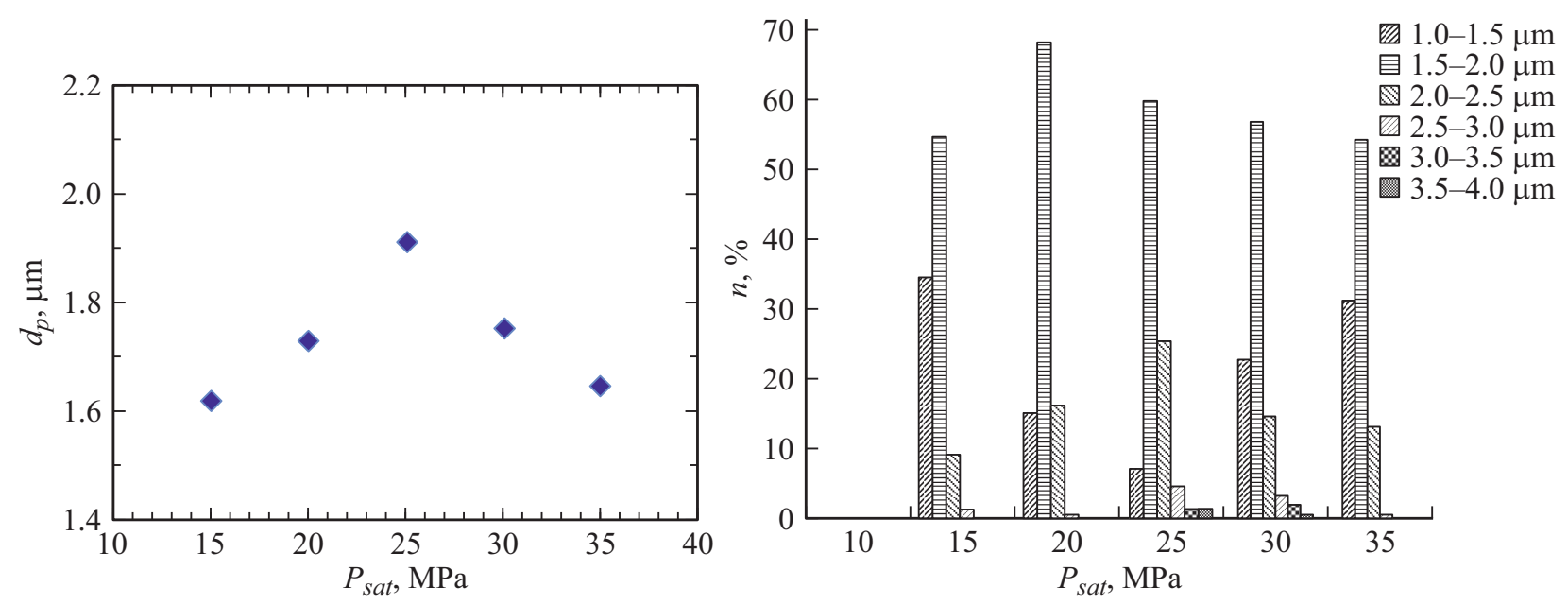

Рис. 5. Зависимость среднего размера частиц от давления в системе и гистограмма распределения среднего размера частиц в серии экспериментов № 4 при температуре насытителя $333 \mathrm{~K}$.

При $10 \mathrm{MPa}$ растворимость лидокаина в сверхкритическом $\mathrm{CO}_{2}$ была очень высокой и именно в результате большей степени пересыщения были получены частицы такого мелкого размера, что их невозможно было рассмотреть в микроскопе, используемом в данном исследовании. В диапазоне давлений экстракции от 15 до $25 \mathrm{MPa} \mathrm{наблюдается} \mathrm{увеличение} \mathrm{размера} \mathrm{частиц.} \mathrm{При}$ больших значениях давления (30 и $35 \mathrm{MPa}$ ) замечена тенденция к уменьшению размера частиц: значительно растет количество частиц с размерами $1-2 \mu \mathrm{m}$ наряду с уменьшением количества частиц с большими размерами.

\section{3. УФ-спектрофотометрический анализ микронизированного местноанестезирующего лекарственного средства. Спектры образцов. Определение пиков}

С помощью УФ-спектрофотометра и ПО Scan54 в ультрафиолетовом диапазоне с задаваемым шагом ска- нирования в $1 \mathrm{~nm}$ были получены спектральные кривые зависимости оптической плотности от длины волны необработанного и обработанного лидокаина в 95\%-ном этаноле (рис. 6) и в фосфатном буферном растворе с pH 7 (рис. 7) [4,5].

В каждом случае поглощение лидокаина находится в области длин волн 200-285 nm. Растворы образцов в спирте (рис. 6) и растворы образцов в буфере (рис. 7) в диапазоне длин волн 200-285 nm дали практически идентичные друг другу картины спектра.

Максимальное поглощение света каждого из исследуемых растворов необработанного и диспергированного методом RESS лидокаина в 95\%-ном этаноле (1.907 и 1.877 соответственно) наблюдалось при длине волны $200 \mathrm{~nm}$ (рис. 6). А при длине волны $202 \mathrm{~nm}$ наблюдался пик у обоих растворов необработанного и микронизированного лидокаина - 2.204 и 1.952 соответственно (рис. 7). 


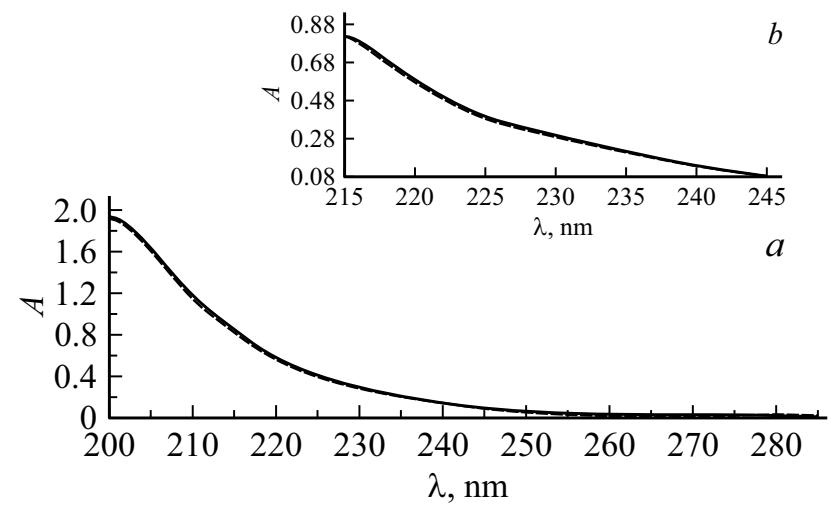

Pис. 6. Спектры поглощения этанольных растворов необработанного и продиспергированного методом RESS лидокаина, шаг сканирования $1 \mathrm{~nm}$. Сплошной линией указан необработанный лидокаин, штриховой - лидокаин, обработанный методом RESS: $a$ - диапазон длин волн $200-285 \mathrm{~nm} ; b-$ увеличенная область УФ-спектра поглощения лидокаина, диапазон длин волн $215-275 \mathrm{~nm}$.

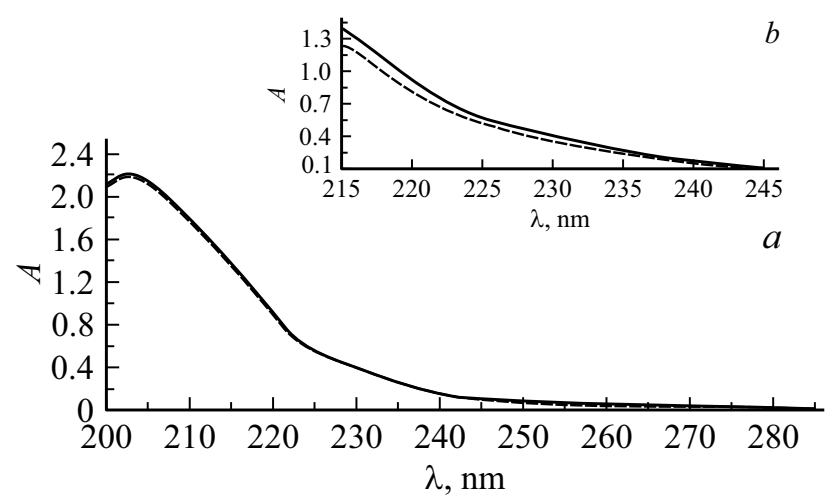

Рис. 7. Спектры поглощения необработанного и продиспергированного методом RESS лидокаина в буферном растворе, шаг сканирования $1 \mathrm{~nm}$. Сплошной линией указан необработанный лидокаин, штриховой - лидокаин, обработанный методом RESS: $a$ - диапазон длин волн $200-285 \mathrm{~nm} ; b-$ увеличенная область УФ-спектра поглощения лидокаина, диапазон длин волн $215-245 \mathrm{~nm}$.

Поскольку в данной области длин волн наблюдается большое рассеяние света, было принято решение исключить из рассмотрения оптическую плотность в области длин волн ниже $215 \mathrm{~nm}$, в спектрах поглощения в этой области длин волн активно поглощают компоненты буферного раствора. Поскольку поглощение света всеми исследуемыми растворами лидокаина является незначительным при длине волны выше $245 \mathrm{~nm}$, выбранное спектральное окно лежало в диапазоне длин волн 215-245 nm. В этой области длины волны растворы лидокаина показывают характерную форму спектра поглощения (рис. $6, b$ и 7, $b$ ).

Согласно ГФ РФ XIV [6], минимальные значения относительной погрешности измерения оптической плотности А принимает при $A=0.434$. Поэтому стараются ра- ботать в диапазоне оптических плотностей $0.3-0.8$, так как на этом интервале оптических плотностей приборы калибруются с наибольшей точностью.

Таким образом, опираясь на эти утверждения, мы приняли решение использовать при работе с этанольным раствором в качестве аналитической длину волны $\lambda=223 \mathrm{~nm}$, при которой $A=0.447$ у обработанного лидокаина, а при работе с буферными растворами $\lambda=228 \mathrm{~nm}$, при которой оптические плотности необработанной и микронизированной фармацевтической субстанции равны соответственно 0.460 и 0.405 .

При сравнительном анализе спектральных кривых зависимости оптической плотности от длины волны необработанного и обработанного лидокаина в обоих растворителях видно, что в рабочих областях спектров совпадают точки максимумов (200 nm для этанола и $202 \mathrm{~nm}$ для фосфатного буферного раствора), плеч и точки перегиба. Спектры практически тождественны друг другу, т.е. фармацевтическая субстанция в ходе обработки методом RESS не подверглась термическому разложению, молекулярной деструкции или каким-либо другим негативным воздействиям. Таким образом, обработанное лекарственное средство признается идентичным оригинальному лидокаину.

\section{4. Результаты теста „Растворения“}

На цифровой магнитной мешалке с подогревом модели WiseStir MSH-20D фирмы DAIHAN Scientific Co. было проведено „Растворение“. Отобранные пробы наливались в кварцевые кюветы и последовательно анализировались с помощью УФ-спектрофотометра. Анализ проводился на ранее найденной аналитической длине волны (при работе с буферными растворами $\lambda=228 \mathrm{~nm}$ ) и с помощью сохраненных файлов с построенными калибровочными графиками. Проводилось измерение оптической плотности анализируемых образцов с последующим определением концентраций.

Целью данного испытания является сравнение уровня растворения оригинальной фармацевтической субстанции и микронизированной методом быстрого расширения сверхкритического раствора. Основным критерием оценки является скорость, с которой лекарственное средство растворится в фосфатном буферном растворе, моделирующим плазму. Результаты теста „Растворение“ занесены в табл. 2 и наглядно представлены на рис. 8. Можно сразу отметить тот факт, что уже в начальный момент времени в фосфатном буферном растворе растворилось большее количество микронизированного методом RESS лидокаина (46\%), нежели его оригинальной, не подвергнувшейся микронизации субстанции $(9.6 \%)$.

Как отмечалось ранее, лекарственное средство будет считаться полностью растворившимся, когда его концентрация в среде растворения достигнет значения 
Таблица 2. Результаты теста „Растворение“

\begin{tabular}{|c|c|c|c|c|c|c|}
\hline \multirow[t]{2}{*}{$t, \min$} & \multicolumn{3}{|c|}{ Необработанный лидокаин } & \multicolumn{3}{|c|}{ Микронизированный лидокаин } \\
\hline & $\alpha, 1 / \mathrm{m}$ & $n_{k}, \mathrm{mg} / \mathrm{ml}$ & $\mathrm{n}, \%$ & $\alpha, 1 / \mathrm{m}$ & $n_{k}, \mathrm{mg} / \mathrm{ml}$ & $n, \%$ \\
\hline 0 & 0.138 & 0.048 & 9.6 & 0.625 & 0.230 & 46.0 \\
\hline 10 & 0.354 & 0.122 & 24.4 & 1.045 & 0.385 & 77.0 \\
\hline 20 & 0.660 & 0.228 & 45.6 & 1.169 & 0.430 & 86.0 \\
\hline 30 & 0.875 & 0.302 & 60.4 & 1.279 & 0.471 & 94.2 \\
\hline 40 & 1.005 & 0.347 & 69.4 & 1.342 & 0.494 & 98.8 \\
\hline 50 & 1.098 & 0.379 & 75.8 & 1.35 & 0.497 & 99.4 \\
\hline 60 & 1.215 & 0.419 & 83.8 & 1.352 & 0.500 & 100 \\
\hline 70 & 1.255 & 0.433 & 86.6 & 1.352 & 0.500 & 100 \\
\hline 80 & 1.298 & 0.448 & 89.6 & 1.352 & 0.500 & 100 \\
\hline 90 & 1.328 & 0.458 & 91.6 & 1.352 & 0.500 & 100 \\
\hline 100 & 1.356 & 0.468 & 93.6 & 1.352 & 0.500 & 100 \\
\hline 110 & 1.375 & 0.474 & 94.8 & 1.352 & 0.500 & 100 \\
\hline 120 & 1.392 & 0.480 & 96.0 & 1.352 & 0.500 & 100 \\
\hline 130 & 1.404 & 0.484 & 96.8 & 1.352 & 0.500 & 100 \\
\hline 140 & 1.428 & 0.493 & 98.6 & 1.352 & 0.500 & 100 \\
\hline 150 & 1.446 & 0.499 & 99.8 & 1.352 & 0.500 & 100 \\
\hline 160 & 1.460 & 0.500 & 100 & 1.352 & 0.500 & 100 \\
\hline 170 & 1.460 & 0.500 & 100 & 1.352 & 0.500 & 100 \\
\hline 180 & 1.460 & 0.500 & 100 & 1.352 & 0.500 & 100 \\
\hline
\end{tabular}

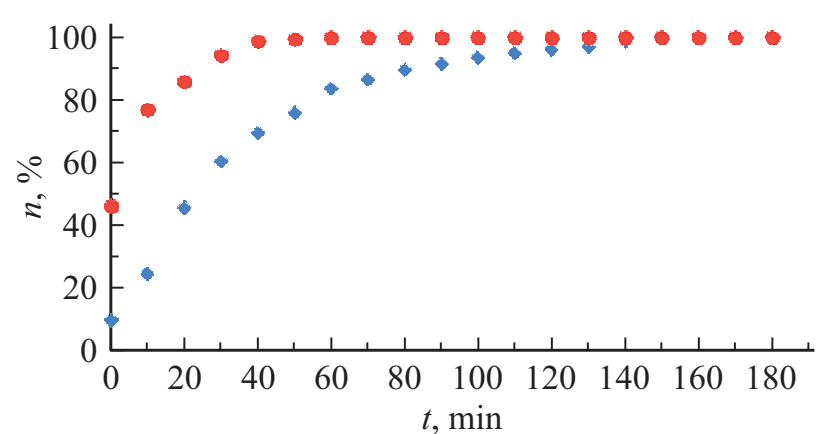

Рис. 8. Динамика растворения. Ромб - необработанный, круг - микронизированный лидокаин.

$0.5 \mathrm{mg} / \mathrm{ml}$. Данного 100\%-ного показателя микронизированный лидокаин достиг спустя $1 \mathrm{~h}$. Хотя, как можно заметить из табл. 2, уже спустя полчаса концентрация его в среде растворения достигала $94.2 \%$, тогда как оригинальное лекарственное средство растворилось лишь на $60 \%$. Полного растворения оно достигло спустя $160 \mathrm{~min}$, т. е. ему потребовалось в 3.2 раза больше времени, чем обработанному лидокаину. Таким образом, микронизация лидокаина методом RESS способствовала увеличению скорости растворения фармацевтической субстанций. В первые полчаса теста „Растворение“ активного терапевтического компонента из микронизированного лидокаина высвободилось более чем в 1.5 раза больше по сравнению с оригинальной формой фармацевтической субстанции. Это позволит добиться уменьшения расхода препарата на приготовление растворов для парентераль- ного введения и ускорить технологический процесс их приготовления.

\section{Заключение}

Было проведено экспериментальное исследование влияния измельчения лидокаина методом RESS на уровень активности. Для реализации данной цели было проведено диспергирование фармацевтической субстанции лидокаина методом RESS в диапазоне давлений 10-35 МРа и температур 308-333 K.

В результате были получены микрочастицы исследуемого лекарственного средства. В ходе анализа размеров частиц полученных порошков микронизированного лидокаина было выявлено, что средний размер частиц существенно зависит от условий проведения опыта (температура, давление).

Проведен спектрофотометрический анализ микронизированного местноанестезирующего лекарственного средства в ультрафиолетовой области спектра. Получены спектры исследуемых образцов. Качественный анализ, направленный на установление подлинности, показал, что в ходе обработки методом RESS фармацевтическая субстанция не подверглась термическому разложению, молекулярной деструкции или каким-либо другим негативным воздействиям. Построены калибровочные графики, пригодные для определения неизвестных концентраций растворов исследуемого вещества в 95\%-ном этаноле и фосфатном буферном растворе. Для приготовления исходного раствора точно взвешивали $100 \mathrm{mg}$ лидокаина, растворяли в этаноле, и объем доводили до $100 \mathrm{ml}$. Затем исходный раствор разводили этанолом до 
необходимых концентраций: $0.05,0.10,0.15,0.20,0.25$, $0.30,0.35,0.40,0.45$ и $0.50 \mathrm{mg} / \mathrm{ml}$. Для построения калибровочного графика при фотометрическом определении продиспергированного лидокаина в фосфатном буферном растворе аналогично были измерены оптические плотности десяти стандартных растворов при тех же концентрациях.

В среде фосфатного буферного раствора, имитирующего плазму, был проведен тест „Растворение“, показавший, что уменьшение размера частиц дало повышенный выход за более короткий промежуток времени по сравнению с оригинальным лекарственным средством, не подвергавшимся обработке.

Таким образом, микронизация лидокаина методом RESS способствовала увеличению объема высвободившегося активного терапевтического компонента микронизированного лидокаина в начальный момент времени и увеличению скорости растворения фармацевтической субстанции. Выполненная работа и полученные в ходе нее результаты подтверждают эффективность использования сверхкритических флюидных технологий для микронизации порошков фармацевтических субстанций, относительно нерастворимых в воде, но находящих широкое применение в терапевтической практике.

\section{Финансирование работы}

Исследование выполнено за счет гранта Российского научного фонда проект 18-79-00064.

\section{Конфликт интересов}

Авторы заявляют, что у них нет конфликта интересов.

\section{Список литературы}

[1] И.М. Гильмутдинов, И.И. Гильмутдинов, И.В. Кузнецова, А.Н. Сабирзянов. ТВТ, 54 (1), 69 (2016).

DOI: $10.7868 / \mathrm{S} 0040364416010026$ [I.M. Gil'mutdinov, I.I. Gil'mutdinov, I.V. Kuznetsova, A.N. Sabirzyanov. High Temperature. 54 (1), 78 (2016).

DOI: https://doi.org/10.1134/S0018151X16010028]

[2] И.В. Кузнецова. Расширение растворов „сверхкритический $\mathrm{CO}_{2}$-метилпарабен“ $u$ „сверхкритический $\mathrm{CO}_{2}$ ибупрофен" через микронные каналы. Автореф. канд. дисс. (КНИТУ, Казань, 2012)

[3] J. Kim, H.-L. Kim, C.-S. Ju Kim. J. Korean J. Chem. Eng., 27, 1139 (2010). DOI: https://doi.org/10.1007/s11814-010-0219-2

[4] Н.М. Тиц. Энциклопедия клинических лабораторных тестов, пер. с англ под ред. В.В. Меньшикова. (Лабиформ, М., 1997), c. 960.

[5] Г.К. Будников, Э.И. Медянцева, С.С. Бабкина. Успехи химии, 60 (4), 881 (1991).

[6] Государственная фармакопея Российской Федеращии $X I V$ изд. (М., Министерство здравоохранения Российской Федерации, 2018), Электронный ресурс. Режим доступа: https://minzdrav.gov.ru/; http://femb.ru/femb/pharmacopea.php 